\title{
Karakteristik Pelepasan Hara N Pupuk yang Terlapisi Lateks-Chitosan
}

\author{
Moh. Hamzah*, K. Eryanti, A. S. Hidayat, dan F. Kurniawati \\ Pusat Teknologi Material - TIEM, BPP Teknologi Kawasan Puspiptek Serpong, Tangerang \\ Selatan, Banten \\ *Email: moh.hamzah@bppt.go.id; Tel.: +62-21-757911324
}

\begin{abstract}
ABSTRAK
Pupuk merupakan salah satu industri prioritas bagi pertanian dan berkontribusi 15 hingga $30 \%$ dalam struktur biaya usaha pertanian padi. Pada penggunaan pupuk di lapangan masih banyak kehilangan unsur hara pada waktu pemupukan di lapangan (sawah) sehingga efisiensi penggunaan pupuk berkurang. Pengembangan dan inovasi teknologi produk pupuk pertanian yang efisien pada saat ini salah satunya adalah memodifikasi pupuk dengan cara pelapisan pada permukaan granul pupuk. Dalam penelitian ini lateks-chitosan digunakan sebagai inhibitor nitrifikasi. Secara umum penelitian suatu bahan melibatkan karakterisasi dengan metoda SEM untuk mengetahui karakteristik mikrografis bahan lateks-chitosan. Lapisan lateks-chitosan mampu memperkuat struktur butiran pupuk saat diuji perendaman dalam air selama 6 bulan. Lapisan tipis lateks-chitosan sebagai inhibitor nitrifikasi pada produk pupuk pertanian memiliki ketebalan sekitar 84,50 - 197,7 $\mu \mathrm{m}$ dan diameter pori sekitar 2,88 - 4,16 $\mu \mathrm{m}$. Jumlah pelepasan hara N pupuk granul NPK 16-16-16 chitosan dilapisi lebih tinggi dari kitosan lateks chitosan.
\end{abstract}

Kata kunci: butiran pupuk, chitosan, inhibitor nitrifikasi, jumlah pelepasan, lateks, pelapisan

\begin{abstract}
One of the priority industries in agriculture is fertilizer that contributes 15 to $30 \%$ in the cost structure of rice farming. In the use of fertilizer in the field there is still much loss of nutrients at the time offertilization in the field (such as paddy field) so that the efficiency of fertilizer decreases, among others, it is caused by nitrification and urease. Currently the development and technology innovation of an efficient agricultural fertilizer products is to modify the fertilizer by coating the nitrification inhibitor on the surface of the fertilizer granules. In this research latex and chitosan were used as the nitrification inhibitor. Generally, the research material involved the characterization by SEM methods to identify the micrographic of materials of latex-chitosan. The latex-chitosan coating was able to strengthen the fertilizer granule structure when it was tested for immersion in water for 6 months. The thin layer of latex-chitosan as nitrification inhibitor on agricultural fertilizer products had thickness of about 84.50 - $197.7 \mu \mathrm{m}$ and pore diameters of about $2.88-4.16 \mu \mathrm{m}$. The release of nutrient $N$ fertilizer granule NPK 16-16-16 coated chitosan was higher than coated latex chitosan.
\end{abstract}

Keywords: release of nutrient, fertilizer granule, nitrification inhibitor, latex, chitosan, coating

\section{PENDAHULUAN}

Pupuk merupakan salah satu industri prioritas bagi pertanian dan berkontribusi 15 hingga $30 \%$ dalam struktur biaya usaha pertanian padi. Kapasitas produksi urea nasional sebesar 8 juta ton pertahun sedangkan kebutuhannya sebesar 9 juta ton per tahun (Fauzi , 2015). 
Pada penggunaan pupuk di lapangan masih banyak kehilangan unsur hara pada waktu pemupukan di lapangan (sawah) sehingga efisiensi penggunaan pupuk berkurang antara lain disebabkan nitrifikasi. Nitrifikasi merupakan aktifitas oksigen atas ammonium-ion $\mathrm{NH}^{+}$pada waktu tertentu. Proses ini menimbulkan dampak berupa volatilisasi ammonia ke udara (Trenkel, 1997).

Hilangnya $\mathrm{N}$ sebagai gas nitrogen karena denitrifikasi, hilangnya $\mathrm{N}$ sebagai gas ammonia karena volatilisasi dan hilangnya $\mathrm{N}$ sebagai nitrat karena tercuci ( leaching ) oleh aliran air. Kehilangan nitrogen karena denitrifikasi diperkirakan mencapai 30-40\%, volatilisasi sekitar 10-20\%, leaching berkisar $44 \%$ dan karena erosi dapat mencapai $45 \%$ (Yoshida and Padre, 1974). Dengan adanya permasalahan tersebut diatas, petani menanggung kerugian biaya pemupukan akibat ketidak efisiensian pupuk.

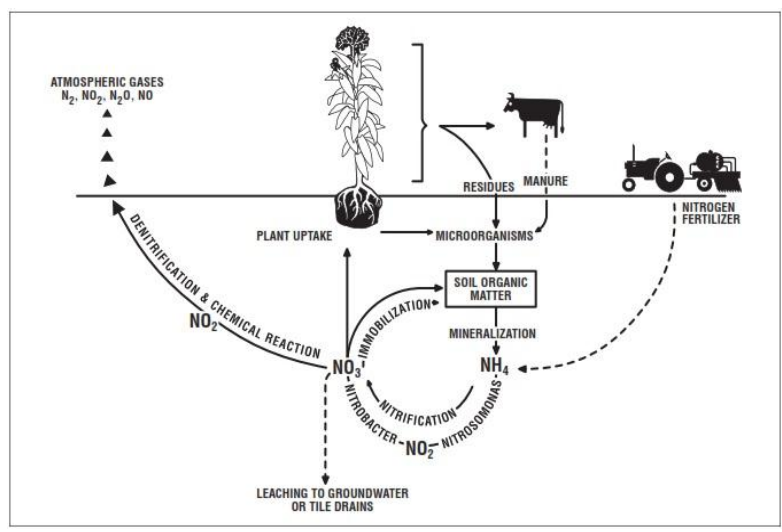

Gambar 1. Siklus penguraian pupuk dan proses nitrifikasi dan urease dalam tanah (Nelson and Huber, 2001)

Modifikasi pupuk dengan pelapisan inhibitor nitrifikasi pupuk pertanian secara komersiil dikenal sebagai pupuk SRF / CRF (slow release fertilizer / controlled release fertilizer) yaitu pupuk lambat lepas / pupuk lepas terkendali.
Secara teknis inhibitor nitrifikasi dan urease yang dimodifikasikan dengan cara pelapisan pupuk dengan bahan yang bereaksi kimia, seperti pupuk ureaformaldehyde, terlihat bahwa proporsi nitrogen yang terkandung dapat dilepaskan ke tanah sangat perlahan (atau bahkan tidak sama sekali).

Sedangkan jika menggunakan bahan polimer jangka waktu yang lama adalah kehilangan dampaknya karakteristik kemampuan tukar kation tanah sebab terhalangi polimer. Penggunaan bahan ini dapat menyebabkan akumulasi yang tidak diinginkan dari residu plastik (hingga $50 \mathrm{~kg}$ per ha dan tahun) (HÄHNDEL, 1997).

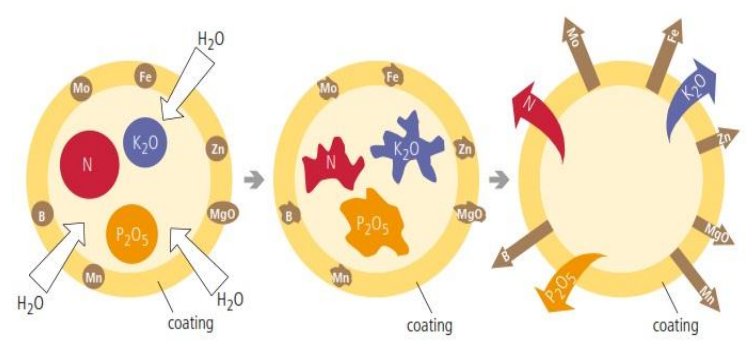

Gambar 2. Proses pelepasan unsur hara pupuk (Hähndel, BASF, 1997).

Secara teknis inhibitor nitrifikasi dan urease yang dimodifikasikan dengan cara pelapisan pupuk dengan bahan yang bereaksi kimia, seperti pupuk ureaformaldehyde, terlihat bahwa proporsi nitrogen yang terkandung dapat dilepaskan ke tanah sangat perlahan (atau bahkan tidak sama sekali).

Sedangkan jika menggunakan bahan polimer jangka waktu yang lama adalah kehilangan dampaknya karakteristik kemampuan tukar kation tanah sebab terhalangi polimer. Penggunaan bahan ini dapat menyebabkan akumulasi yang tidak diinginkan dari residu plastik (hingga $50 \mathrm{~kg}$ per ha dan tahun) (HÄHNDEL, 1997). 
Bahan lain yang terbuat dari starch juga digunakan dalam pembuatan pupuk urea lepas lambat pupuk urea lepas lambat dalam bentuk granul yang menggunakan zeolit alam, dimana pupuk urea powder dimixture atau dicampur dengan zeolit alam powder sebagai matriksnya dan digranulasi dengan menggunakan binder starch (Hamzah, 2007). Pelepasan urea beriringan dengan proses hidrolisis yang mana pelemahan ikatan binder starch akibat intrusi air. Proses yang sama dilakukan pada pembuatan pupuk majemuk lepas lambat menggunakan zeolit alam dengan cara memblending unsur hara NPK dari urea, $\mathrm{KCl}$, $D A P$, dan Zeolit Alam (Hamzah, 2007). Secara komersiil penggunaan starch sebagai binder masih dapat berfluktusi harganya, karena merupakan bagian dari bahan baku pangan.

Terdapat beberapa penelitian tentang pemanfaatan chitosan untuk penggunaan di bidang pertanian. Chitin dan chitosan walapun tidak terlarutkan dalam air namun dapat terdegradasi secara fotodegradasi karena gugus amine menyerap sinar $U V$ saat mana tanah pertanian tidak teririgasikan (Mucha and Pawlak, 2002). Kemampuan teknis chitin dan chitosan terhadap aplikasi pertanian antara lain sebagai ; biosida (fungisida, bakterisida, insektisida, dan lain lainnya), pupuk nitrogen, biostimulant atau pengatur pertumbuhan (Sharp, 2013).

\section{METODE PENELITIAN}

\section{Bahan}

Bahan bahan yang digunakan dalam penelitian ini adalah lateks segar dengan KK (kandungan kering) 60\% dengan spesifikasi teknis sebagai berikut:
Tabel 1. Spesifikasi lateks

\begin{tabular}{ll}
\hline Dry Rubber Content & $60,04 \%$ \\
\hline Total Solid Content & $61,29 \%$ \\
\hline Volatile Fatty Acid & 0,021 \\
\hline Kadar amonia & 0.73 \\
\hline $\begin{array}{l}\text { Mechanical Stability } \\
\text { Time }\end{array}$ & $800-900$ \\
\hline Viskositas & 105 \\
\hline
\end{tabular}

Chitosan yang berasal dari PT. Biotech Surindo Indramayu dengan spesifikasi teknis sebagai berikut:

Tabel 2. Spesifikasi teknis chitosan.

\begin{tabular}{lll}
\hline \multicolumn{1}{c}{ Item } & \multicolumn{1}{c}{$\begin{array}{c}\text { Specification } \\
\text { Standart }\end{array}$} & \multicolumn{1}{c}{$\begin{array}{c}\text { Test } \\
\text { Result }\end{array}$} \\
\hline Grade & $\begin{array}{l}\text { Food } \\
\text { grade }\end{array}$ \\
\hline Apperance & Light bown & Off white \\
\hline Particle size & Flake-Powder & $\begin{array}{l}30 \quad-40 \\
\text { mesh }\end{array}$ \\
\hline $\begin{array}{l}\text { Degree of } \\
\text { deacetylation }\end{array}$ & $85-89 \%$ & $85,89 \%$ \\
\hline Viscosity & $20-500 \mathrm{cPs}$ & $141,5 \mathrm{cPs}$ \\
\hline $\begin{array}{l}\text { Moisture } \\
\text { content }\end{array}$ & $\leq 10 \%$ & $9,75 \%$ \\
\hline Ash content & $\leq 1,5 \%$ & $1,48 \%$ \\
\hline pH $(1 \%)$ & $7-8$ & complies \\
\hline
\end{tabular}

Asam asetat $1 \%$ digunakan sebagai pelarut chitosan, kemudian pupuk NPK 16-16-16 komersiil berbentuk granul.

\section{Formula lateks-chitosan}

Ditentukan berdasarkan perbandingan persentase kandungan lateks dengan kandungan chitosan. Formula lateks-chitosan ditentukan seperti di tabel bawah ini: 
Tabel 3. Formula lateks-chitosan.

\begin{tabular}{cc}
\hline Lateks $(\%)$ & Chitosan $(\%)$ \\
\hline 0 & 100 \\
\hline 20 & 80 \\
\hline
\end{tabular}

Pembuatan formula lateks-chitosan 20:80 :

- Larutan 1\% chitosan dibuat dengan melarutkan 1 gram chitosan dalam larutan asam asetat $1 \%$ sampai menghasilkan 100 $\mathrm{ml}$ larutan chitosan. Lalu diambil $80 \mathrm{ml}$ (kadar kering chitosan 0.8 gr)

- Kemudian 0.33 gr lateks (kadar kering lateks 0.2 gr) didispersikan dengan air distilasi.

- Kedua bahan tersebut dicampurkan menjadi cairan formula lateks-chitosan 20:80.

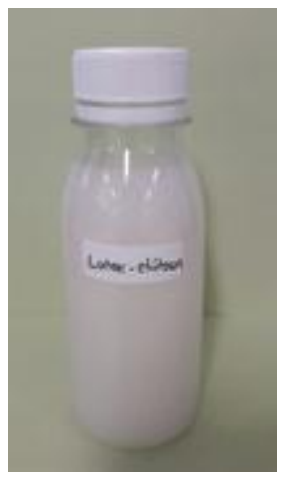

Gambar 3. Prototipe cairan larutan latekschitosan 20:80

Cairan formula lateks-chitosan digunakan sebagai bahan coating pada produk pupuk pertanian disemprotkan pada permukaannya.

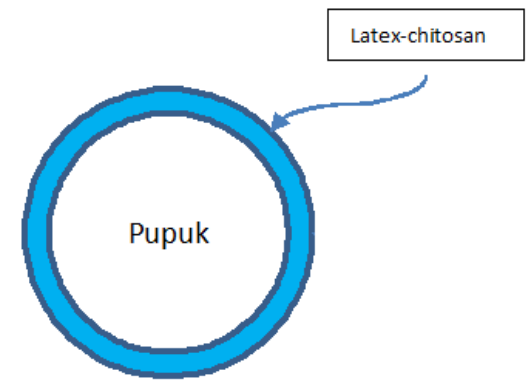

Gambar 4. Diskripsi lapisan lateks-chitosan
Sesudah itu dilanjutkan proses pengeringan yang dilakukan untuk menguapkan kandungan air dari lateks-chitosan dalam oven.
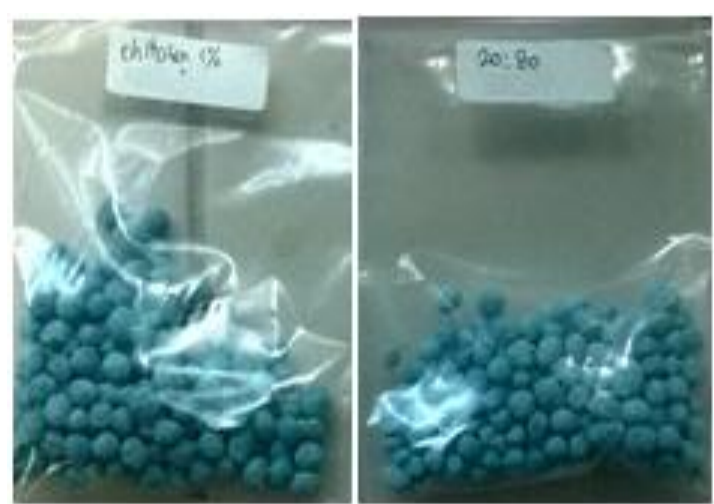

Gambar 5. Granul pupuk yang dilapisi chitosan dan latek-chitosan.

\section{Pengujian Jumlah Pelepasan Hara}

Pengujian jumlah pelepasan hara $\mathrm{N}$ dilakukan dengan metoda perkolasi sebagai pemodelan kondisi seperti siraman hujan di bawah ini

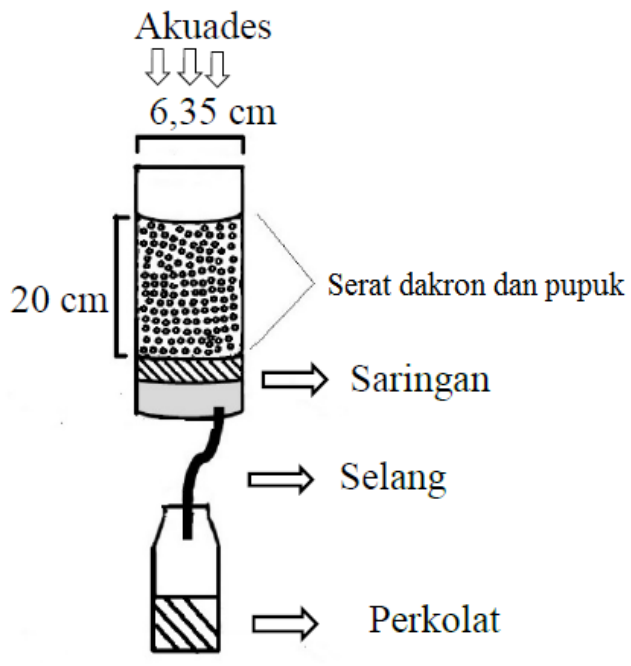

Gambar 6. Pengujian jumlah pelepasan hara N dengan merode perkolasi (Handayani 2014).

Setiap pekan dilakukan 3 kali penyiraman dengan menggunakan akuades sebanyak $100 \mathrm{ml}$. Kemudian nitrogen pada perkolat diukur setiap pekan yang terakumulasi dengan menggunakan metode $U V$ vis spectroscopy. 


\section{Peralatan}

Dalam karakterisasi dengan metoda SEM parameter yang ditetapkan dalam pengamatan struktur mikrografis lapisan yang terbentuk pada permukaan granul pupuk adalah ketebalan lapisan dan pori-pori, menggunakan peralatan Scanning Electron Microscopy merk JEOL seri JSM-6510LA.

Untuk mengukur kadar hara $\mathrm{N}$ yang terlarut menggunakan $U V$-vis spectrocopy.

\section{HASIL DAN PEMBAHASAN}

Hasil mikrografis SEM dari lapisan chitosan, terlihat adanya antar aglomerasi partikel chitosan membentuk pori pori.

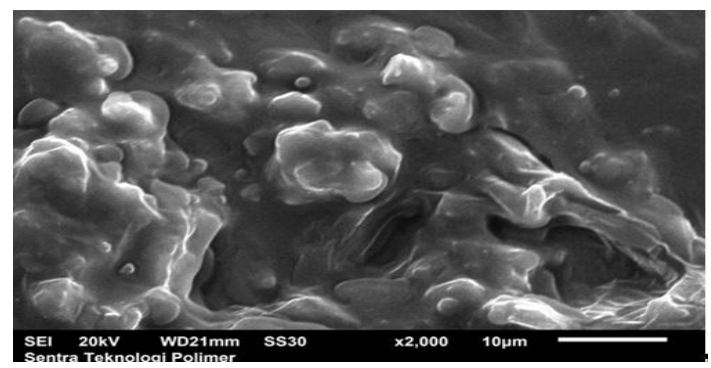

Gambar 7. Pola mikrografis lapisan chitosan

Ukuran partikel serbuk chitosan yang dilarutkan dalam asam asetat diduga mempengaruhi pembentukan struktur serat lapisan chitosan selama dalam proses pengeringan. Selain itu konsentrasi pelarutan chitosan dalam asam asetat $1 \%$ berdampak pada pembentukan pola serat aglomerasi dibanding dengan serat sebelum dilarutkan.

Pada lapisan lateks menunjukkan mempunyai pola serat lamela paralel dan ukuran pori-porinya yang sangat kecil.

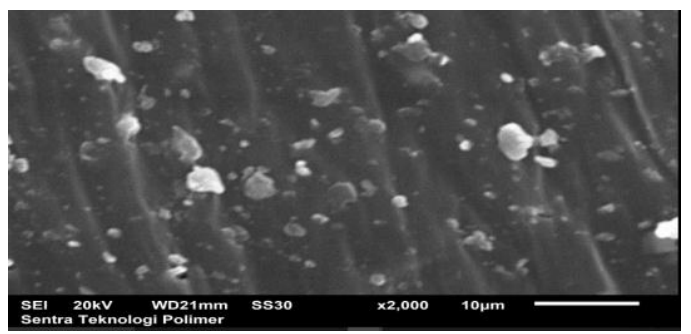

Gambar 8. Pola mikrografis lapisan lateks
Oleh sebab itu pada saat chitosan dan lateks diformulakan maka lapisan lateks-chitosan yang terbentuk berpola heterogen seperti yang terlihat di bawah ini:

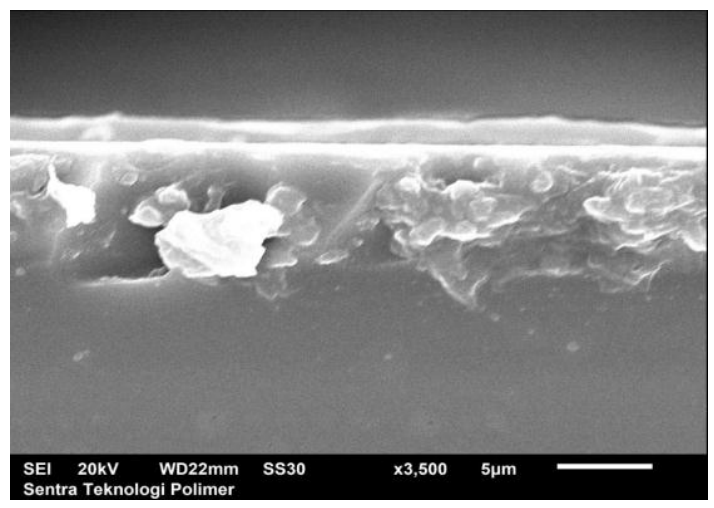

Gambar 9. Pola mikrografis lapisan lateks -chitosan $20: 80$
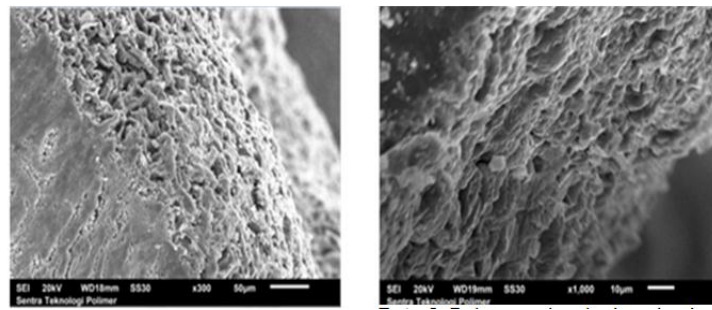

Gambar 10. Pola mikrografis pori-pori chitosan dan lateks-chitosan

Pengamatan lapisan chitosan dan lateks-chitosan yang terbentuk pada permukaan granul produk pupuk dapat dilihat pada gambar 10 yang menunjukkan bahwa lapisan yang terbentuk mengikuti kontur permukaan granul pupuk. Di samping itu lapisan chitosan dan lateks-chitosan menutupi pori-pori granul pupuk yang ada membentuk pori-pori berdasarkan pori-pori lapisan chitosan dan lateks-chitosan.
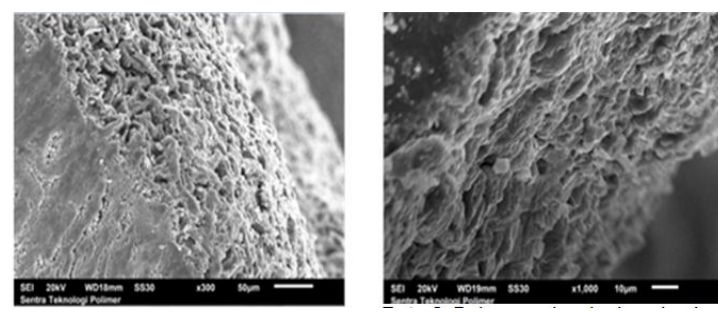

Gambar 11. Pola mikrografis pori-pori chitosan dan lateks-chitosan 
Hasil pengukuran ketebalan lapisan chitosan dan lateks-chitosan dijelaskan pada tabel di bawah ini:

Tabel 4. Ketebalan lapisan coating latekschitosan pada permukaan pupuk NPK

\begin{tabular}{llc}
\hline No. & $\begin{array}{c}\text { Lateks-chitosan } \\
\text { formula }\end{array}$ & Thickness $(\boldsymbol{\mu m})$ \\
\hline 1. & $0: 100$ & 197.798 \\
\hline 2. & $20: 80$ & 84.501 \\
\hline
\end{tabular}

Kemudian pengukuran diameter pori-pori yang dihasil dari pelapisan lateks-chitosan pada permukaan granul produk pupuk pertanian adalah:

Tabel 5. Diameter pori-pori lapisan lateks-chitosan pada permukaan pupuk

\begin{tabular}{lcc}
\hline No. & $\begin{array}{c}\text { Lateks-chitosan } \\
\text { formula }\end{array}$ & $\begin{array}{c}\text { Diameter } \\
\text { pore-pori }(\boldsymbol{\mu m})\end{array}$ \\
\hline 1. & $0: 100$ & 2.880 \\
\hline 2. & $20: 80$ & 4.160 \\
\hline & Pengujian & selanjutnya adalah
\end{tabular}

perendaman granul pupuk yang sudah dilapisi lateks-chitosan ini dimaksudkan untuk memenuhi kriteria pupuk slow release fertilizer yakni tahan terhadap tekanan permukaan oleh air dan menghitung waktu ketahanannya sampai berkeping keping.

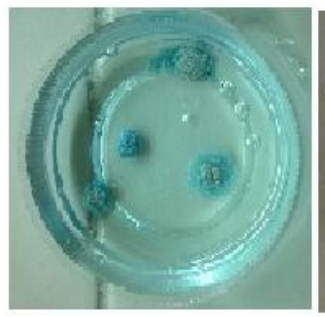

(a)

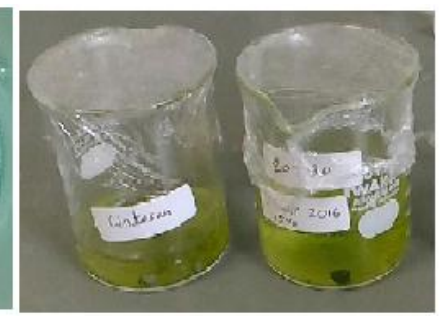

(b)
Gambar 12. Pengujian perendaman granul pupuk (a) before and (b) after lateks chitosan coating.

Hasil ini dapat mengungkapkan kemampuan lapisan lateks-chitosan yang melapisi permukaan granul pupuk, di mana kemampuan ketahanan struktur granul tahan terhadap tekanan air tercatat sudah teramati 6 bulan granul pupuk yang dilapisi lateks-chitosan belum hancur. Pengujian sebelumnya sudah menunjukkan ketahanan struktur granul yang terlapisi chitosan dan lateks-chitosan teramati 3 bulan (Sudirman et al, 2016). Dalam pengujian digunakan perbandingan granul pupuk pertanian NPK 16-16-16 komersiil yang mana rata-rata 5 detik sudah hancur dalam air.

Sebagai acuan dalam melakukan perhitungan karakteristik pelepasa hara $\mathrm{N}$ didapatkan bahwa kandungan hara $\mathrm{N}$ dari 1 gram pupuk NPK 16-16-16 komersiil adalah $160 \mathrm{mg}$, sehingga persentase pelepasan hara $\mathrm{N}$ dari pupuk NPK 16-16-16 yang terlapisi chitosan dan lateks-chitosan selama 1 bulan / 4 pekan sebagai berikut:

Tabel 6. Jumlah pelepasan hara $\mathrm{N}$ selama 1 bulan

\begin{tabular}{lll}
\hline $\begin{array}{l}\text { Formula lateks-chitosan, } \\
\%\end{array}$ & $0: 100$ & $20: 80$ \\
\hline $\begin{array}{l}\text { Jumlah pelepasan hara } \\
\mathrm{N}, \mathrm{mg}\end{array}$ & 103.26 & 100.83 \\
\hline $\begin{array}{l}\text { Persentase hara N yang } \\
\text { terlepaskan }\end{array}$ & $64.54 \%$ & $63.02 \%$ \\
\hline
\end{tabular}

Karakteristik jumlah pelepasan hara $\mathrm{N}$ pupuk granul dilapisi dengan chitosan didapatkan sebesar 103.26 miligram. Grafik pola pelepasan dapat dilihat di bawah ini:

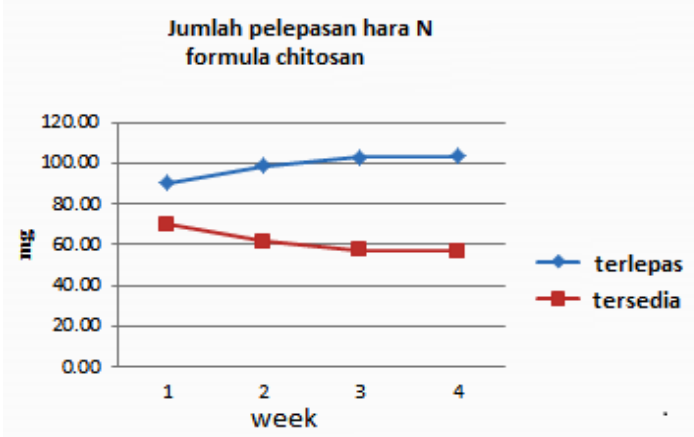

Gambar 13. Jumlah pelepasan hara $\mathrm{N}$ formula 0:100 (chitosan). 
dan dengan lateks-chitosan is 100.83 miligram selama 1 bulan perendaman.

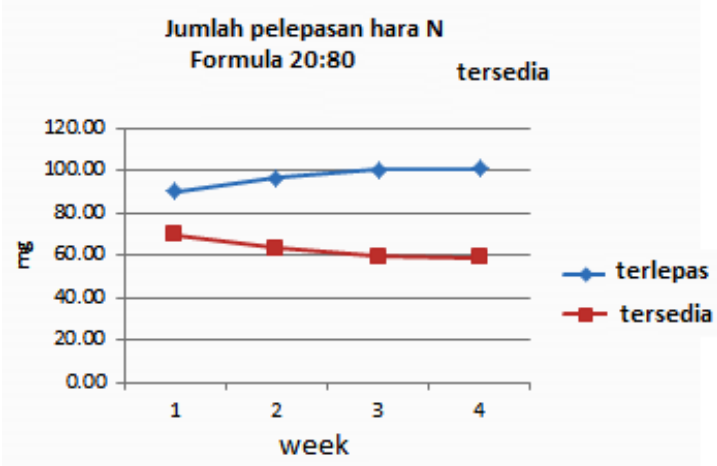

Gambar 14. Jumlah pelepasan hara $\mathrm{N}$ formula 20:80.

Dan persentase pelepasanhara $\mathrm{N}$ dari granul pupuk NPK fertilizer 16-16-16 yang dilapisi chitosan adalah $64,54 \%$ dan yang dilapisi lateks-chitosan sebesar 63,02 \% selama 1 bulan perendaman.

Dengan diketahuinya pola pelepasan hara $\mathrm{N}$ dalam 1 bulan atau 4 pekan pertama selanjutnya dapat diperkirakan pola pelepasan hara $\mathrm{N}$ pada 1 bulan berikutnya dan seterusnya.

\section{SIMPULAN DAN SARAN}

\section{Simpulan}

Dari hasil penelitian ini dapat diambil kesimpulan sebagai berikut:

- Pelapisan lateks-chitosan pada permukaan produk pupuk memiliki ketipisan antara 84.50 sampai $197.7 \mu \mathrm{m}$ dan diameter pori pori antara 2.88 sampai $4.16 \mu \mathrm{m}$.

- Uji ketahanan dalam air pada produk pupuk yang dilapisi lateks-chitosan mampu terhadap tekanan air selama 6 bulan sehingga memenuhi kriteria pupuk slow release fertilizer.

- Karakteristik jumlah pelepasan hara N dari pupuk granul NPK 16-16-16 yang dilapisi chitosan sebesar $103.26 \mathrm{mg}$, lebih tinggi dari pada yang dilapisi lateks chitosan yakni $100.83 \mathrm{mg}$ selama periode 1 bulan.

\section{Saran}

Dalam pengembangan SRF lebih lanjut lateks-chitosan disampaikan beberapa saran antara lain :

- Perlu dilakukan uji efektifitas dan efisiensi pemupukan pada tanaman sesuai dengan karakteristik pelepasan hara $\mathrm{N}$ pupuk yang terlapisi lateks-chitosan secara green house.

Kajian kemungkinan lateks-chitosan sebagai binder dalam pengembangan formula SRF yang disesuaikan karakteristik pertumbuhan tanaman tertentu (padi, jagung, dan lain lainnya).

\section{UCAPAN TERIMA KASIH}

Peneliti dan rekan mengucapkan terima kasih atas terlaksananya penelitian ini kepada Menteri Riset Teknologi dan Dikti yang telah memberi dana penelitian melalui Program Insinas tahun 2016-2017.

\section{DAFTAR PUSTAKA}

Anonim, 2008, Chitosan: Apakah manfaat chitosan? Naturakos III (7) :10-12.

Fauzi, A., 2015, Menperin: Pemerintah Terus Dorong Pengembangan PupukTitleof Site. Portal Berita Ekonomi: https://www.wartaekonomi.co.id/rea d51134/menperin-pemerintah-terus-d orong-pengembangan-pupuk.html(ac cessed on $28^{\text {th }}$ March 2015).

Handayani, L., 2014, Formulasi Pupuk Lepas Terkendali Menggunakan Pelapisan Akrilik dan Kitosan serta Aplikasinya pada Pembibitan Acacia crassicarpa, Thesis, Sekolah Pascasarjana, Program Studi Agroteknologi Tanah, Institut Pertanian Bogor.

Hähndel, R. (BASF), 1997, Reply to the request on controlled-release fertilizers. Personal communication.

Rosjidi M., Mustafa A., Saputra H., Hamzah M., Tandirerung M., Senda S.P., Gesang M., Sulaksono, Jatiningsih 
D., Sitorus S., Pratolo E., Sulastri, Jufri A., Suwardi. Sertifikat Paten. Nomor Paten : ID P0023827. Pembuatan Pupuk Urea Lepas Lambat Dalam Bentuk Granul Yang Menggunakan Zeolit Alam dan Proses Pembuatannya. Kementerian Hukum dan Hak Asasi Manusia. Indonesia. 2007.

Mustafa A., Saputra H., Tandirerung M., Gesang M., Jatiningsih D., Sitorus S., Rosjidi M., Hamzah M., Jufri A., Sulaksono, Sulastri. Bayu H.S. Sertifikat Paten. Nomor Paten : ID P0027121. Pembuatan Pupuk Majemuk Lepas Lambat Menggunakan Zeolit Alam. Kementerian Hukum dan Hak Asasi Manusia. Indonesia. 2010.

Mucha, M. And Pawlak A., 2002, Complex study on chitosan degradability, Polymery. 47: 7-8.

Muzzarelli, RAA., 1977, Chitin, Pergamon. Oxford, Chapter 6.

Nelson, D.W. and Huber, D., 1992, Nitrification Inhibitors for Corn Production. Crop Fertilizer, National Corn Handbook, Iowa State University USA.
Sudirman H., Hamzah M., Hidayat A. S., Kalembang E., Fitriani D.A., 2016,Making the Nitrification Inhibitor with Latex Chitosan Raw Material for Agricultural Fertilizers Products, SOJ Materials Science \& Engineering. ISSN: 2372-0964. DOI: http://dx.doi.org/10.15226/sojmse.20 16.00129 .

Sharp R.G., 2013, A Review of the Applications of Chitin and Its Derivatives in Agriculture to Modify Plant-Microbial Interactions and Improve Crop Yields, Agronomy3. 757-793, 2013. doi:10.3390/ agronomy 3040757.

Struszczyk, MH., 2002, Applications of chitosan. Polymery. 47:396-340.

Trenkel, M. E., 1997, Controlled-Release and Stabilized Fertilizers in Agriculture, the International Fertilizer Industry Association: Paris, France, December 1997, ISBN 2-9506299-0-3.

Yoshida, T. And Padre B. C., 1974, Nitrification and Denitrification in Submerged Maahas Clay Soil, Soil Science. 